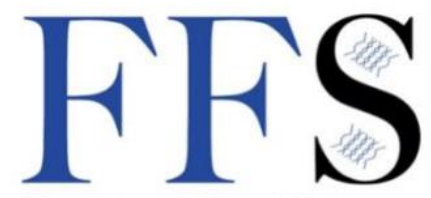

Functional Food Science

\title{
Aging in HIV: Can natural compounds beneficially affect its higher progression?
}

\author{
Reza Rastmanesh ${ }^{1}$, Maki Osato ${ }^{2}$, Surajit Pathak ${ }^{3}$, Antara Banerjee ${ }^{3}$, Saida Rasulova ${ }^{4}$, Francesco \\ Marotta $^{4 *}$
}

\begin{abstract}
${ }^{1}$ The Nutrition Society, London, UK; ${ }^{2}$ Oxidative Stress Lab, Osato Research Institute, Gifu, Japan; ${ }^{3}$ Faculty of Allied Health Sciences, Chettinad Hospital \& Research Institute, Chettinad Academy of Research and Education; ${ }^{4}$ ReGenera R\&D International for Aging Intervention, Milan, Italy
\end{abstract}

*Corresponding Author: Francesco Marotta, PhD, ReGenera R\&D International for Aging Intervention, Milan, Italy

Submission Date: November 22 ${ }^{\text {nd }}, 2021$; Acceptance Date: November 26th, 2021 ; Publication Date: November $29^{\text {th }}, 2021$

Please cite this article as: Rastmanesh R., Osato M., Pathak S., Banerjee A., Rasulova S., Marotta F. Aging in HIV: Can natural compounds beneficially affect its higher progression? Functional Food Science 2021; 1(11): 82-85. DOI: https://www.doi.org/10.31989/ffs.v1i11.868

\section{EDITORIAL}

Aging in HIV patients is accompanied with many physical and psychological health threatening challenges. A full citation of all natural compounds and their beneficial effects in aging process in HIV-positive patients is beyond the scope of a short editorial like this and we do not intend to delve in depth of genetic pathways. However, we shortly present some useful notes below worth of ongoing research.

Ancillary antiretroviral therapy (ART) has been shown in the past 15 years or more to improve quality and life expectancy of people with HIV [1]. However, this therapy meanwhile leads to an increased oxidative stress, which in turn deteriorates lipid, and carbon metabolism, renal disease, liver function, and most importantly enhanced risk of endothelial/cardiovascular diseases [2] and ocular problems [3].

The sad point is that adverse effects produced by some medications create an endless vicious cycle per se; and this is while HIV patients already have to simultaneously take multiple drugs. The issue becomes even more pronounced when aging phenomenon is supervening. One may add other concurring and complicating scenarios such as Covid-19 pandemic and enormous burden imposed by such scenarios, when considering that the stress induced by prolonged house 
restriction per se is affecting immune system, oxidative stress, and proper dietary habits. Based on a report to the NIH Office of AIDS Research by the HIV and Aging Working Group [4], polypharmacy is one of the most deteriorating factors threatening both physical and psychological status of people infected with HIV, particularly in aged people. Furthermore, another recent knowledge, attitude, and practice (KAP) study shows that, in principle, most patients tend to prefer nutraceuticals/supplements over drugs in terms of cost, compliance, and feeling healthy.

There is a wide range of natural compounds which may enhance the efficacy of HIV therapy [5]. For instance, we have elsewhere hypothesized that prebiotics and probiotics have the potential to enhance the efficacy of HIV vaccination through over-expression of heat shock proteins (HSPs) in humans [6]. Although, there are not sufficient published works to perform a comprehensive review, researchers are encouraged to consider this interesting topic. It can be hypothesized that different pre/probiotics and functional foods [7] might influence different HSPs in a different manner and therefore viral infections patho-mechanisms, consequently. Bearing this in mind, it was very recently reported that prebiotics and probiotics appreciably benefit patients with COVID19 [8-9].

In a longitudinal pilot study performed in HIV-1 patients who were receiving probiotic supplement twice a day for 6 months, it was found that this supplementation could significantly promote a reduction in T-cell activation, an increase in Th17 frequencies, and a recovery of intestinal epithelium integrity and mitochondrial morphology in ART-treated HIV-1-positive patients. These findings highlight the beneficial properties of probiotic supplementation for the reconstitution of physical and immunological integrity of the mucosal intestinal barrier in ART-treated HIV-1-positive patients [10].

Tryptophan, another natural amino acid, is tremendously catabolized in chronic viral infections such as HIV [11]. Furthermore, kynurenine pathway of tryptophan metabolism is altered in many aging diseases such as neuroinflammatory and neurodegenerative diseases, including AIDS-related dementia [12].

It has been reported that HIV patients develop a 1.75-fold increased race- and sex-adjusted incidence of intermediate-stage age-related macular degeneration [ARMD] compared with that found in an HIV-uninfected cohort [13]. Indeed, sleep disorders is another annoying problem in aged HIV patients. Over 10 years ago, Rastmanesh, had envisaged the potential of melatonin to treat or prevent ARMD through stimulation of telomerase activity [14] and several clinical trials have been carried out ever since [15].

Another major issue in aged HIV-positive patients is endothelial dysfunction and redox dysfunction. We previously tested a bio-fermented nutraceutical (FPP) that has been previously shown to positively modulate nitric oxide (NO). In a placebo-controlled clinical study involving forty-two healthy middle-aged participants given 3 grams of FPP three times a day for 6 weeks, a significant increase in plasma NO and Flow-mediated dilation (FMD) and a decrease in asymmetrical dimethylarginine (ADMA) were observed [16].

The approach to redox dysfunction in HIV patients has been for long time a tantalizing topic with scattered data, often of limited investigational depth. The last extensive review on the boon of antioxidants was published in 2015 envisaging the need for patents study on antioxidants and immune modulators to treat HIV/AIDS [17].

In this regard, this year we retrospectively reviewed the data related to $11 \mathrm{HIV}$ patients under ART 
and no food supplement who had been concomitantly administered FPP-ORI (ongoing work submitted as congress presentation at The Lancet Summit, 2021). Patients (10/1, m/f, age range 41-66), had comparable dietary pattern and duration of ART (38-73 months). The treatment regimen consisted of two nucleoside reverse transcriptase inhibitors plus another active drug. Their median CD4+ cell count was 578 cells/ $\mu$ and the viral load was undetectable. All subjects were on FPP-ORI 4, 5gr twice a day orally for the past 7-11 months. At their first visit and when recalled, CDKN2A gene expression, telomerase length and activity were measured by real-time quantitative PCR and telomerase repeats amplification protocol, respectively. Urinary $80 \mathrm{HdG}$ was also measured. The preliminary results showed that the shorter telomere length vs healthy control [T/S ratio: $0.97 \pm 0.01$ vs. $1.13 \pm 0.009$, $(p<0.001)$ was not modified. If not for a trend increase of telomerase However, while CD2NKA expression was increased in HIV subjects than in control $(0.47 \pm 0.03$ vs. $0.35 \pm 0.05, p<0.05)$, FPP-co-treated subjects showed a significant downregulation of CDKN2A $(p<0.05)$. This beneficial modulation of CDKN2A expression is of interest when considering that this gene is regarded to be a marker associated to cellular senescence more robustly than telomerase dynamics which is liable to be

\section{REFERENCES}

1. Yoshimura K. Current status of HIV/AIDS in the ART era. J Infect Chemother. 2017; 23:12-16.

2. Miranda Perez AA, Gutierrez Perez ME, Urraza Robledo Al, Delgadillo GD, Ruiz FP, Lopez Marquez FC: Klotho-HIV and Oxidative Stress: The Role of Klotho in Cardiovascular Disease Under HIV Infection-A Review. DNA Cell Biol 2020;39:14781485.

3. Ng WT, Versace P: Ocular association of HIV infection in the era of highly active antiretroviral therapy and the global perspective. Clin Exp Ophthalmol 2005;33:317-329.

4. High KP, Brennan-Ing $\mathrm{M}$, Clifford DB, Cohen MH, Currier J, Deeks SG, Deren S, Effros RB, Gebo K, Goronzy JJ, Justice AC, affected by ART per se. Abnormal values of urinary $80 \mathrm{HdG}$ ( $p<0.01$ vs. control) were also normalised by FPP-ORI supplementation $(\mathrm{p}<0.05)$.

Although the small sample size did not allow establishing a possible correlation with age or CD4+ cell counts and the duration is still too limited to infer the clinical relevance of these FPP-induced biological events, these data confirm the worthiness to pursue also in HIV subjects well-structured studies on functional foods/supplements in the health strategies and whose unique peculiarity has been recently restated by Martirosyan et al. [18]. This is of particular importance elderly HIV who are more exposed to premature senescence with cognitive impairment and liable to have a lower intake of antioxidants independently of their virologic status.

The time is ripe to launch a new topic on the capacity of natural compounds as a complementary medicine to specifically address quality and life expectancy of people with HIV. Future in-depth studies may also explore the interactions between natural compounds and Klotho gene (as a putative agesuppressing gene) in an attempt to figure out mechanistic pathways.

Landay A, Levin J, Miotti PG, Munk RJ, Nass H, Rinaldo CR, Jr., Shlipak MG, Tracy R, Valcour V, Vance DE, Walston JD, Volberding P: HIV and aging: state of knowledge and areas of critical need for research. A report to the NIH Office of AIDS Research by the HIV and Aging Working Group. J Acquir Immune Defic Syndr 1-7-2012;60 Suppl 1:S1-18.

5. Cary DC, Peterlin BM. Natural Products and HIV/AIDS. AIDS Res Hum Retroviruses. 2018;34:31-38.

6. Marotta F, Rastmanesh R, Catanzaro R, Bomba A, Allegri F: Potential of prebiotics and probiotics to enhance the efficacy of HIV vaccination: a working hypothesis. Clinic Pharmacol Biopharmaceut 2012;1:e102. 
7. Marotta F, Koike K, Lorenzetti A, Naito Y, Fayet F, Shimizu H, Marandola P. Nutraceutical strategy in aging: targeting heat shock protein and inflammatory profile through understanding interleukin-6 polymorphism. Ann N Y Acad Sci. 2007 Nov;1119:196-202.

8. Bottari B, Castellone V, Neviani E. Probiotics and Covid-19. Int J Food Sci Nutr. 2021 May;72[3]:293-299.and raise defenses against SAR S-CoV-2. Minerva Med 2020;111:281-283.

9. Jayawardena $R$, Sooriyaarachchi $P$, Chourdakis $M$, Jeewandara C, Ranasinghe P: Enhancing immunity in viral infections, with special emphasis on COVID-19: A review. Diabetes Metab Syndr 2020;14:367-382.

10. d'Ettorre G, Rossi G, Scagnolari C, Andreotti M, Giustini N, Serafino S, Schietroma I, Scheri GC, Fard SN, Trinchieri V, Mastromarino P, Selvaggi C, Scarpona S, Fanello G, Fiocca F, Ceccarelli G, Antonelli G, Brenchley JM, Vullo V: Probiotic supplementation promotes a reduction in T-cell activation ,an increase in Th17 frequencies, and a recovery of intestinal epithelium integrity and mitochondrial morphology in ARTtreated HIV-1-positive patients. Immun Inflamm Dis $2017 ; 5: 244-260$

11. Mehraj V, Routy JP: Tryptophan Catabolism in Chronic Viral Infections: Handling Uninvited Guests. Int J Tryptophan Res $2015 ; 8: 41-48$

12. Lovelace MD, Varney B, Sundaram G, Franco NF, Ng ML, Pai S, Lim CK, Guillemin GJ, Brew BJ: Current Evidence for a Role of the Kynurenine Pathway of Tryptophan Metabolism in Multiple Sclerosis. Front Immunol 2016;7:246.

13. Jabs DA, Van Natta ML, Pak JW, Danis RP, Hunt PW. Incidence of Intermediate-stage Age-related Macular Degeneration in Patients With Acquired Immunodeficiency Syndrome. Am J Ophthalmol. 2017 Jul;179:151-158.

14. Rastmanesh R: Potential of melatonin to treat or prevent agerelated macular degeneration through stimulation of telomerase activity. Med Hypotheses 2011;76:79-85.

15. Sletten TL, Magee M, Murray JM, Gordon CJ, Lovato N, Kennaway DJ, Gwini SM, Bartlett DJ, Lockley SW, Lack LC, Grunstein RR, Rajaratnam SMW: Efficacy of melatonin with behavioural sleep-wake scheduling for delayed sleep-wake phase disorder: A double-blind, randomised clinical trial. PLoS Med:15;2018 e1002587.

16. Marotta F, Yadav H, Kumari A, Catanzaro R, Jain S, Polimeni A, Lorenzetti A, Soresi V: Cardioprotective effect of a biofermented nutraceutical on endothelial function in healthy middle-aged subjects. Rejuvenation Res 2012;15:178-181.

17. Singh G, Pai RS. Dawn of antioxidants and immune modulators to stop HIV-progression and boost the immune system in HIV/AIDS patients: Anupdated comprehensive and critical review. Pharmacol Rep. 2015; 67:600-5.

18. Martirosyan D, von Brugger J, Bialow S. Functional food science: Differences and similarities with food science. Functional Foods in Health and Disease, 2021; 11[9]:408 